\title{
Assistência de enfermagem ao portador de Hanseníase: abordagem transcultural
}

Nursing assistance to a Leprosy-infected patient: transcultural approach

Asistencia de enfermería al portador de Lepra: abordaje transcultural

\section{Fernando José Guedes da Silva Júnior', Riassa Dourado Ferreira', Olívia Dias de Araújo", Sônia Maria de Araújo Camêlo', Inez Sampaio Nery"}

'Faculdade Santo Agostinho. Teresina, PI

"Universidade Federal do Piauí. Teresina, PI

Submissão: 05/10/2008

Aprovação: 20/10/2008

\section{RESUMO}

Trata-se de um estudo de caso, desenvolvido em um Centro de Saúde em Teresina - PI, Que abordou a problemática da assistência de enfermagem prestada a uma paciente com Hanseníase Multibacilar, enfocando o cuidado de Enfermagem Transcultural, Diagnósticos e Intervenções de Enfermagem segundo a Taxonomia II da NANDA. Realizou-se a entrevista semi-estruturada e observação participante, Que possibilitaram a coleta dos dados, os Quais foram tratados baseados nos padrões normativos, valores e prática diárias, modos de cuidado popular e cuidados reQueridos no sistema profissional. Neste estudo, constatou-se Que o planejamento da assistência de enfermagem visou, principalmente, contribuir para a adesão ao tratamento da doença, diminuindo os riscos potenciais e utilizando a preservação, negociação e re-padronização do sistema profissional. Observou-se também a adesão ao tratamento e a realização de autocuidado voltado para a hanseníase de forma culturalmente satisfatória.

Descritores: Hanseníase; Cuidados de enfermagem; Enfermagem transcultural.

\section{ABSTRACT}

This is a case study, developed in a health center in Teresina-PI, which dealt with the issue of nursing assistance given to a patient with Multibacillary Leprosy, focusing on the Transcultural Nursing care, Diagnosis and Nursing Interventions according to NANDA Taxonomy II. A semi-structured interview and participant observation were carried out, which enabled data collection handled according to normative patterns, values and daily practices, ways of popular care and cares required in the professional system. In this study, we realized that nursing assistance planning aimed, especially, to contribute on the disease treatment support, reducing potential risks and using preservation, negotiation and re-standardization of the professional system. We also observed the support to the treatment and the development of self care turned to leprosy in a culturally satisfactory way.

Descriptors: Leprosy; Nursing care; Transcultural nursing.

\section{RESUMEN}

Es un estudio de caso, desarrollado en un centro de salud en Teresina-PI, Que abordó la problemática de la asistencia de enfermería dada a una paciente con lepra multibacilar, enfocando el cuidado de Enfermería Transcultural, Diagnósticos, e Intervenciones de Enfermería segundo la Taxonomía II de NANDA. Se realizó una entrevista semi-estructurada y observación participante, Que posibilitaron la colecta de los datos, los cuales fueron tratados basados em los padrones normativos, valores y prácticas diárias, modos de cuidado popular y cuidados requeridos en el sistema profesional. En este estudio, se constató que el planeamiento de la asistencia de enfermería objetivó, principalmente, contribuir para la adhesión al tratamiento de la enfermidad, disminuyendo los riscos potenciales y utilizando la preservación, negociación y repradonización del sistema profesional. Se observó también la adhesión al tratamiento y la realización del auto cuidado com la lepra de forma culturalmente satisfactória.

Descriptores: Lepra; Atención de enfermería; Enfermería transcultural. 


\section{INTRODUÇÃO}

A Hanseníase, ao longo da história, foi descrita como uma doença Que causava horror, em decorrência, das deformidades físicas relacionados ao doente não tratado, Que ocasionou estigma e preconceito dos mais diversos. Na história da humanidade, provavelmente nenhuma doença gerou estigma social tão intenso Quanto à Hanseníase, sempre associada a conceitos tais como: pecado, impureza e punição(l).

A Hanseníase constitui uma patologia das mais antigas que atua no organismo humano, com indícios remotos que datam de 600 a.C. e procedem da Ásia, Que juntamente com a África podem ser consideradas o berço da doença ${ }^{(2)}$.

Nesse contexto, o estigma se refere à desqualificação e à marginalização social, em função, principalmente, das deformidades físicas do paciente. Uma vez Que, um indivíduo é estereotipado com tal rótulo social, Que significa impor-lhe uma marca Que, de certo modo, o reduz a uma condição inferior ao padrão mínimo atribuído à condição humana, restaria a ele duas possibilidades: ou se adequar ao papel marginal a ele designado ou tentar "encobrir" as marcas Que caracterizam o estereótipo estigmatizante ${ }^{(3)}$

O preconceito resulta do modo de ver o mundo, das apreciações de ordem moral e valorativa, dos diferentes comportamentos sociais e mesmo das posturas corporais. Pode-se, assim, inferir Que estes são produtos de uma herança cultural e referindo à cultura, deve-se destacar Que, de acordo com Leininger ${ }^{(4)}$, esta se define a partir dos valores, crenças, normas de comportamento e práticas relativas ao estilo de vida, aprendidos, compartilhados e transmitidos por um grupo específico, Que orienta o pensamento, as decisões e as ações dos elementos pertencentes ao grupo.

Assim, é importante relatar que o conhecimento do senso comum é mantido pela cultura, ao longo do tempo, e serve para orientar a tomada de decisões dos membros da sociedade, suscitando um retrocesso na percepção sócio-cultual da doença.

A Hanseníase constitui uma doença infectocontagiosa crônica causada pelo Mycobacterium leprae. E caracteriza-se por uma evolução lenta, alta infectividade e baixa patogenicidade, manifestando-se, principalmente, através de sinais e sintomas dermatoneurológicos, variando em espectro entre dois pólos estáveis (tuberculóide e virchowiano), com formas intermediárias instáveis. Uma classificação operacional, para fins de tratamento, reúne os doentes em dois grupos: os paucibacilares e os multibacilares. É importante ressaltar Que, de acordo com essa classificação, definese o tratamento com a poliquimioterapia (PQT) estabelecida pela Organização Mundial de Saúde (OMS) $)^{(5,6)}$.

Admite-se ser a principal forma de contágio da Hanseníase a inter-humana e o maior risco de contágio é a convivência domiciliar com o doente bacilífero. Destaca-se Que a principal via de eliminação dos bacilos é a aérea superior, especificamente o trato respiratório é a mais provável via de entrada do agente etiológico no corpo ${ }^{(7,8)}$.

A estratégia adotada pelos países membros da OMS definiu, em 1991, Que a Hanseníase deixaria de ser um problema de saúde pública naqueles países onde o coeficiente de prevalência fosse menor ou igual a I caso para cada 10 mil habitantes. No entanto, a hanseníase ainda não foi eliminada dos continentes africano, asiático e sul-americano ${ }^{(9)}$.

Nos países endêmicos, como o Brasil, observam-se diferenças na prevalência entre regiões, estados, microrregiões, municípios, concentrando-se nos locais de maior pobreza. Sabe-se Que as condições sócio-econômicas e culturais têm grande influência na distribuição e propagação da endemia hansênica. A situação epidemiológica da Hanseníase, em vista da sua heterogeneidade mostra Que, em 2005, a Região Norte foi a Que apresentou o maior coeficiente, com o correspondente a 4,02 casos por 10 mil habitantes, seguida da Região Centro-Oeste, com 3,29 casos por 10 mil habitantes. Já a região Nordeste apresentou 2, 14 casos por 10 mil habitantes. Em contrapartida, o Sudeste manifestou 0,60, caso e o Sul, 0,53 caso por 10 mil habitantes. Os principais indicadores de monitoramento de eliminação da Hanseníase apontam para uma melhor situação da Região Sul em relação à Região Norte, contudo, os coeficientes de detecção continuam elevados no Brasil e América Latina ${ }^{(10-13)}$.

Portanto, tal heterogeneidade pode ser claramente vista através dos índices hiperendêmicos do Estado do Piauí, uma vez Que, há uma grande variação de seus indícios Quando comparados com a prevalência nacional, tendo em vista Que no Estado o coeficiente de prevalência é de 10,60 por 10 mil habitantes. Em relação ao município de Teresina, os dados de prevalência no ano de 2004 foram 13,92/10.000 habitantes, o Que representa um percentual maior Que o do próprio Estado e considerado muito alto, Quando aplicado o critério da $\mathrm{OMS}^{(7)}$.

Baseado nos aspectos epidemiológicos denota-se que a Hanseníase representa um importante problema de saúde pública em todo o Brasil, pois, aliados às prevalências, encontram-se outros fatores, como a evolução crônica, a capacidade de provocar lesões incapacitantes ou deformantes e, principalmente, a facilidade de proliferação dos focos de infecção.

Nesse sentido, os agravos devem ser diminuídos através de políticas públicas Que visem o controle e/ou eliminação da doenças. E assim, a Estratégia Saúde da Família (ESF) passa a constituir um dos principais eixos responsáveis por realizar tais medidas preventivas e curativas, visto que a ESF prevê um atendimento multiprofissional à saúde da população de sua área adscrita, inserindo-se no primeiro nível de ações e serviços do sistema local de assistência à saúde: a atenção básica. Essa nova estratégia nasce alicerçada em princípios Que, se realmente respeitados, serão capazes de provocar a transformação necessária para reorganização das ações e serviços de saúde, em específico, promover a redução das prevalências de Hanseníase no Brasil ${ }^{(14)}$.

Desse modo, é função da(o) Enfermeira(o) da ESF proporcionar uma educação continuada dos auxiliares e técnicos de enfermagem, bem como dos agentes comunitários de saúde, e principalmente, realizar consultas de enfermagem Que proporcionem, dentre outras funções, a identificação dos fatores de risco e de adesão no tratamento da hanseníase. Nessa perspectiva, segundo Leopardi ${ }^{(15)}$, é imprescindível na ESF uma perspectiva cultural em que a Enfermagem relacione o cuidado e sua influência na assistência, funcionando como suporte na facilitação e capacitação a indivíduos ou grupos, para manter ou reaver o seu bem-estar ou ajudá-los a enfrentar dificuldades ou a morte, de uma forma culturalmente significativa e satisfatória.

Partindo desse enfoque, elegeu-se a Teoria Transcultural, de Madeleine Leininger, Que foi articulada a partir de 1978, para tentar dar conta da problemática Que envolve o sujeito portador de Hanseníase e da assistência de enfermagem prestada a esse sujeito. 
Baseado nesta Teoria, destaca-se Que o cuidado é a essência da prática e do conhecimento, incluindo assistir, dar suporte e facilitar atos para atender necessidades.

O cuidado é cultural, pois cada povo tem seu próprio jeito de cuidar, considerando como diversidade do cuidado. Nessa perspectiva, para uma assistência adęuada, a(o) enfermeira(o) pode avaliar os comportamentos de cuidados culturais, decidindo com a pessoa se são preserváveis, mutáveis ou negociáveis.

Destaca-se como preserváveis aqueles cuidados já praticados por um indivíduo, família ou grupo, benéficos ou mesmo inócuos para a saúde. No entanto, na negociação suas ações e decisões dão subsídio para facilitar a assistência das pessoas de uma determinada cultura, além de promover a adaptação ou acomodação com os provedores de saúde profissionais. Por outro lado a repadronização constitui ações e decisões Que auxiliam os indivíduos ou grupos a reordenar, trocar ou em grande parte modificar seus modos de vida para o novo, o diferente, beneficiando os padrões de cuidado à saúde ${ }^{(4)}$.

Em suma, essa Teoria, tem como proposta principal proporcionar o cuidado em consonância com a cultura, numa abordagem holística, focalizando a enfermagem científica e humanista. Partindo, pois, dessa proposta teórica ressalta-se que o objetivo desta pesquisa é relatar a assistência de enfermagem prestada a uma paciente com Hanseníase, utilizando uma abordagem Transcultural.

E nesse sentido, este estudo é relevante por procurar contribuir, de forma consistente, para o desenvolvimento de um corpo de conhecimento próprio em enfermagem relacionado à assistência prestada ao portador de Hanseníase. Além disso, se justifica por procurar proporcionar um maior conhecimento e envolvimento do profissional enfermeiro com uma situação real observada e refletir sobre o interesse dos profissionais em organizar o seu trabalho, possibilitando estabelecimento de ações na análise da história do paciente.

Destaca-se ainda Que a partir da inserção contextual desta pesquisa se poderá conhecer a realidade mais profunda Que circunscreve a problemática em Questão, a assistência de enfermagem prestada ao paciente hanseniano, no sentido de direcionar a tomada de decisões na tentativa de mobilizar o compromisso de melhoria do cuidado em saúde e possibilitar a definição de estratégias Que promovam e fortaleçam a interação entre a equipe de saúde e o sujeito portador da doença.

\section{METODOLOGIA}

Trata-se de uma pesquisa do tipo estudo de caso. A decisão por desenvolver este estudo de caso se deu mediante a observação de um problema Que merecia uma investigação mais aprofundada, tendo em vista Que a portadora de hanseníase, sujeito deste estudo, se encontrava em estágio avançado da doença. Contudo evidencia-se Que embora o relato da assistência de enfermagem prestada à paciente hanseniana constitua foco central da pesquisa, ao desenvolver o estudo de caso, não se pode restringir a investigação ao foco de atenção, considerando-se Que se busca entender não somente o Que aconteceu ou Qual o problema, mas também como, por Que e Qual a sua relação com as outras alterações identificadas e principalmente Qual a assistência prestada a essa paciente, Que reQuer uma avaliação de maneira integral e individualizada, tendo em vista não apenas o seu estado físico, mas principalmente o estado emocional da paciente, considerando, assim, seus aspectos biopsicossociais.

Este estudo fora desenvolvido em abril de 2008, na zona norte de Teresina-PI, no Centro de Saúde Mafrense, Que atende um número definido de famílias, localizadas em uma área geográfica delimitada. O estudo teve com propósito de relatar a assistência de enfermagem prestada a uma paciente com Hanseníase Multibacilar, enfocando o cuidado de Enfermagem Transcultural. É importante explicitar Que, para o desenvolvimento deste estudo foram respeitados os princípios da Resolução 196/96, no Que se refere à pesQuisa com seres humanos, sendo realizado após leitura e assinatura do Termo de Consentimento Livre e Esclarecido.

No primeiro contato com a cliente foi explicado o objetivo do estudo e como seria realizado. Após confirmação de aceite, foi iniciada a entrevista clínica semi-estruturada e preenchimento do histórico, contendo informações subjetivas (anamnese) e objetivas (exame físico).

Para atender ao objetivo da pesquisa foi necessário Que se construísse um instrumento de coleta de dados, para servir de guia de orientação para os pesQuisadores, permitindo o direcionamento e o registro das observações realizadas e assegurando Que não fossem omitidos dados considerados essenciais para investigar e explorar a problemática evidenciada.

Nesse sentido, utilizou-se inicialmente a entrevista semiestruturada e observação participante para a coleta os dados, os Quais foram tratados baseados nos padrões normativos, valores e práticas diárias, modos de cuidado popular e cuidados requeridos no sistema profissional.

Além disso, foram observados os diagnósticos de enfermagem, intervenções e avaliação da assistência proporcionada Que constavam no prontuário da paciente, após consentimento pela equipe responsável.

\section{APRESENTAÇÃO DO ESTUDO DE CASO}

Trata-se de uma paciente do sexo feminino de 85 anos, casada, dona de casa, aposentada, raça branca, sete filhos, protestante (Igreja Messiânica), diagnosticada na Unidade Básica de Saúde, ESF- 187 (Teresina-PI), em 12/08/2007, apresenta-se com sintomas Que nos remetem à Hanseníase multibacilar.

Consciente $(G l a s g o w=15)$, orientada, fásica, deambulando, normotérmica $\left(35,8^{\circ} \mathrm{C}\right)$, hipertensa estágio I ( $\left.130 / 90 \mathrm{mmHg}\right)$, normosfígma (82bpm), taQuipnéica (25 rpm), anictécrica, desidratada $(+++)$, presença de fragmentos de pele exibindo epiderme com retificação dos cones interpapilares e derme com formações granulomatosas com células epitelióides e células gigantes, em conseqüência, vê-se manchas discrômicas e aglomerado de placas (multibacilares) Que variam de $1,5 \times 2 \mathrm{~cm}$ a $19 \times 9 \mathrm{~cm}$. Depreende-se diminuição na sensibilidade tátil e dolorosa das lesões variando entre hipoestésias e anestésica, além de ressecamento da mucosa ocular, pupilas aniscóricas e, à direita, fotorreagente, campo visual prejudicado, opacidade da córnea, Queixando-se constantemente de lacrimejamento e visão turva. Outro fato observado diz respeito à ausência de comprometimento da cartilagem nasal e perfuração do septo, infiltrações ou úlceras na mucosa e ressecamento nasal. Portanto, subtende-se, a presença de acometimentos nos nervos 


\begin{tabular}{|l|l|l|}
\hline $\begin{array}{l}\text { Data de Nascimento: 13/05/1923 } \\
\text { Etnia: Branca } \\
\text { Estado civil: casada }\end{array}$ & $\begin{array}{l}\text { Diagnóstico clínico: Hanseníase Multibacilar } \\
\text { Queixa Principal: Manchas na pele, ausência de } \\
\text { sensibilidade } \\
\text { Data da Entrevista: 03/06/2008 }\end{array}$ \\
\hline Padrões normativos, valores e práticas diárias. & \multicolumn{1}{|c|}{$\begin{array}{c}\text { Modelo de } \\
\text { cuidado popular }\end{array}$} & $\begin{array}{c}\text { Cuidados requeridos no sistema } \\
\text { profissional }\end{array}$ \\
\hline $\begin{array}{l}\text { Protestante (lgreja Messiânica), fanática, } \\
\text { assídua (Ix/semana), possui um "colar" Que } \\
\text { ninguém pode tocar o "Ohikare". }\end{array}$ & $\begin{array}{l}\text { Johrei (técnica utilizada pelo } \\
\text { movimento religioso, consiste, } \\
\text { segundo os adeptos, no ato de } \\
\text { purificar o espírito do homem pela } \\
\text { energia do fogo, predominante na luz } \\
\text { do "Supremo Deus"), Ohikari } \\
\text { (medalha, presa por um cordão } \\
\text { colocado no peito do adepto, através } \\
\text { desta a Luz de Deus é canalizada). }\end{array}$ & $\begin{array}{l}\text { Preservação: religião, lazer, vínculos } \\
\text { familiares. }\end{array}$ \\
\hline $\begin{array}{l}\text { Alimenta-se 5x/dia, não ingere mamão, pois } \\
\text { relata, sempre, gripe após a ingestão, não } \\
\text { gosta de sopas. Dorme 7h/dia e repouso após } \\
\text { o almoço. Refere vontade de realizar práticas } \\
\text { de exercícios diários, mas os efeitos colaterais } \\
\text { das drogas. }\end{array}$ & $\begin{array}{l}\text { Para diminuição das câimbras e dores } \\
\text { musculares realiza massagens, faz uso } \\
\text { de meias, eleva constantemente as } \\
\text { pernas. }\end{array}$ & $\begin{array}{l}\text { Negociação: a realização do } \\
\text { tratamento, o uso de medicamentos, } \\
\text { o apoio e a supervisão da família } \\
\text { para realização do tratamento, em } \\
\text { específico, a administração das doses } \\
\text { diárias dos fármacos. }\end{array}$ \\
\hline $\begin{array}{l}\text { Desidratada (++ +), manchas discrômicas e } \\
\text { aglomerado de placas, diminuição na } \\
\text { sensibilidade tátil e dolorosa, ressecamento da } \\
\text { mucosa ocular e nasal, espessamento dos } \\
\text { nervos radial, fibular comum e tibial posterior, } \\
\text { diminuição da força motora. }\end{array}$ & $\begin{array}{l}\text { Faz uso de sapatos com salto alto e } \\
\text { meias para diminuir a incidência de } \\
\text { câimbras musculares nos membros } \\
\text { inferiores. }\end{array}$ & $\begin{array}{l}\text { Repadronização: orientações Quanto } \\
\text { à dieta, sedentarismo, higiene, } \\
\text { cuidados pessoais e aQueles } \\
\text { relacionados aos efeitos decorrentes } \\
\text { do uso da medicação. }\end{array}$ \\
\hline
\end{tabular}

Quadro I. Coleta de dados segundo o referencial de Leininger ${ }^{(4)}$.

\begin{tabular}{|l|l|}
\hline \multicolumn{1}{|c|}{ Diagnóstico de Enfermagem } & \multicolumn{1}{|c|}{ Prescrições de Enfermagem } \\
\hline $\begin{array}{l}\text { Disposição para bem-estar espiritual aumentado relacionado a } \\
\text { uma fonte sagrada: participação de atividades religiosas; relata } \\
\text { experiências místicas e rezas. }\end{array}$ & Apoiar as práticas espirituais da pessoa. \\
\hline $\begin{array}{l}\text { Volume de líquidos deficiente evidenciado por diminuição do } \\
\text { turgor da pele, pele/mucosa secas, ingestão oral de líquidos } \\
\text { insuficiente relacionado a falha dos mecanismos reguladores. }\end{array}$ & $\begin{array}{l}\text { Fornecer instruções escritas e verbais sobre os líeuidos } \\
\text { desejados e as Quantidades, explicar a necessidade de } \\
\text { aumentar os líeuidos durante infecção e uso de medicação } \\
\text { como denota o caso. }\end{array}$ \\
\hline
\end{tabular}

\section{Quadro 2. Demonstração do Planejamento de Enfermagem,segundo a Taxonomia II da NANDA ${ }^{(16)}$}

periféricos, trigêmeo e facial, e na avaliação da boca constatou-se xerostomia, ou seja, diminuição na produção de saliva.

Ao avaliar os membros superiores e inferiores, pôde ser verificado o espessamento e endurecimento dos nervos radial, fibular comum e tibial posterior, conseeüentemente, constatou-se ressecamentos, ferimentos, cicatrizes, dormência, redução da força muscular e edemas. Entretanto, durante a avaliação da marcha verificou-se a ausência de comprometimento neural (neurite). Ressalta-se ainda, diurese espontânea e eliminações intestinais regulares ( 1 x/dia).

A paciente realiza tratamento de doze meses, com doses mensais supervisionadas, esQuema multibacilar: combinação da rifampicina (600mg/mês supervisionadas), dapsona (dose mensal de 100mg supervisionada e uma dose diária auto-administrada) e de clofazimina (uma dose mensal de $300 \mathrm{mg}$, com administração supervisionada e dose diária de 50mg auto-administrada). É importante explicitar Que, o tratamento pode ser realizado em até dezoito meses.

Em decorrência da possibilidade de infecção dos contatos diretos com a paciente infectada, realizou-se a avaliação clínica, Que inclui: avaliação dermatológica, neurológica dos sete contatos diretos, através da anamnese apenas um dos contatos apresentou sintomatologias características da hanseníase, a Qual foi encaminhada para o Centro de referência Maria Imaculada para realizar exames laboratoriais, Que dão maiores subsídios para a conclusão de um diagnóstico mais fidedigno.

\section{CONSIDERAÇÕES FINAIS}

A partir dos resultados desta pesquisa, constatou-se na paciente deste estudo a relutância em aceitar o diagnóstico, o tratamento e as orientações em todo o curso da avaliação clínica de Enfermagem inserida na Hanseníase. No entanto, após a implementação do Processo de Enfermagem com uma abordagem cultural usando-se dos cuidados no sistema profissional de preservação, negociação e repadronização, a paciente aceitou realizar o tratamento prescrito após autorização vertical do Ministro da Igreja Messiânica da Qual é adépta. Nessa perspectiva, a Enfermeira, o paciente e a família foram 
ativamente envolvidos durante o processo do cuidar e se tornaram co-responsáveis pela busca de cuidados congruentes, evitando-se uma imposição dos mesmos.

O cuidado cultural foi preservado, na medida em Que religião, lazer e vínculos familiares a ajudaram na manutenção do seu bemestar. Já a negociação do cuidado foi pontual em relação ao uso dos medicamentos, haja vista a obstinação da paciente, bem como a necessidade de supervisão das doses diárias por um familiar. A repadronização do cuidado cultural se deu na implementação de orientações e intervenções pela(o) Enfermeira(o) da ESF.

A paciente do estudo apresentou-se capaz de dar continuidade ao tratamento, além de realizar o autocuidado em alguns momentos de forma satisfatória. Entretanto, fez-se necessário ainda realizar ações orientadas Que favorecessem de forma mais eficaz sua saúde. Nesse sentido, as ações de enfermagem realizadas no estudo não se limitaram apenas a esta paciente, mas a todas as intervenções realizadas pela enfermagem numa visão crítica, reflexiva, holística e humanista.

Portanto neste estudo de caso, evidenciou-se que o planejamento da assistência de enfermagem foi decisivo e objetivou, principalmente, contribuir para a adesão ao tratamento da doença, diminuindo os riscos potenciais e utilizando a preservação, negociação e repadronização do sistema profissional.

Observou-se também a realização de autocuidado voltado para a hanseníase de forma culturalmente satisfatória, refletindo na justificativa e importância do estudo, considerando-se Que este procurou possibilitar um maior conhecimento e envolvimento da(o) profissional enfermeira(o) com uma situação real observada e refletir sobre o interesse dos profissionais em organizar o seu trabalho, permitindo estabelecimento de ações na análise da história do paciente.

\section{REFERÊNCIAS}

1. Talhari S, Neves RG, Penna GO, de Oliveira MLV. Hanseníase. Manaus: Gráfica Tropical; 2006.

2. Cole ST, Eiglmeier K, Parkhill J, James KD, Thomson NR, Wheeler $\mathrm{PR}$, et al. Massive gene decay in the leprosy bacillus. Nature 200I;409:1007-II.

3. Claro LBL. Hanseníase: representações sobre a doença. Rio de Janeiro: Editora Fiocruz; 1995.

4. Leininger M. Transcultural Care Diversity and Universality: a theory of nursing. Nursing Health Care 1991; 6(4): 209-12.

5. Beiguelman B. Genética e Hanseníase. Ciência \& Saúde. 2002; 7: 117-28.

6. Ministério da Saúde (BR). Guia brasileiro de vigilância epidemiológica. Brasília: Ministério da Saúde; 2002.

7. Ministério da Saúde (BR). Secretaria de Políticas de Saúde. Departamento de Atenção Básica. Hanseníase: descrição da doença. Brasília: Ministério da Saúde; 2007.

8. Veronesi R, Focaccia R. Tratado de Infectologia. São Paulo: Atheneu; 2007.

9. Who. World Health Organization. Leprosy global situation. Wkly Epidemiol Rec 2005.

10. Miistério da Saúde (BR). Secretaria de Vigilância em Saúde.

Ministério da Saúde. Meta do Ministério da Saúde em relação à hanseníase é de um caso por 10 mil habitantes até final de 2005. Brasília: Ministério da Saúde; 2005.

1 I. Ignotti E. O paradoxo dos indicadores de monitoramento da eliminação da hanseníase [tese]. Rio de Janeiro (RJ): Escola Nacional de Saúde Pública, Fundação Oswaldo Cruz; 2004.

12. Lana FCF, Amaral EP, Lanza FM, Lima PL, Carvalho ACN, Diniz LG. Hanseníase em menores de 15 anos no Vale do JeQuitinhonha, Minas Gerais, Brasil. Rev Bras Enferm 2007; 60(6): 696-700.

13. Meima A, Gupte MD, Van Orrtmarssen G), Habbema JD. Trends in leprosy case detection rates. Int I Lepr Other Mycobact Dis 1997; 65: 305-19.

14. Cortez EA, Tocantins FR. Em busca de uma visão antropológica no Programa de Saúde da Família. Rev Bras Enferm 2006; 59(6): 800-4.

15. Leopardi MT. Teoria e método em assistência de enfermagem. Florianópolis: Soldasoft; 2006.

16. North American Nursing Diagnosis Association. Diagnósticos de enfermagem da NANDA: definições e classificação 20072008. Porto Alegre: Artmed; 2007. 